Technological University Dublin

DÜBLIN

ARROW@TU Dublin

2008-01-01

\title{
Raman Spectroscopy for the Characterization of the Polymerization Rate in an Acrylamide-based Photopolymer
}

\author{
Raghavendra Jallapuram \\ Technological University Dublin, mrutic@gmail.com \\ Izabela Naydenova \\ Technological University of Dublin, izabela.naydenova@tudublin.ie \\ Hugh Byrne \\ Technological University of Dublin, hugh.byrne@tudublin.ie
}

See next page for additional authors

Follow this and additional works at: https://arrow.tudublin.ie/cieoart

\section{Recommended Citation}

Raghavendra, R. et al. (2008) Raman spectroscopy for the characterization of the polymerization rate in an acrylamide-based photopolymer. Applied Optics, Vol. 47, no. 2, pp. 206-212. doi:10.1364/

A0.47.000206

This Article is brought to you for free and open access by the Centre for Industrial and Engineering Optics at ARROW@TU Dublin. It has been accepted for inclusion in Articles by an authorized administrator of ARROW@TU

Dublin. For more information, please contact

arrow.admin@tudublin.ie, aisling.coyne@tudublin.ie, gerard.connolly@tudublin.ie.

Funder: Enterprise Ireland

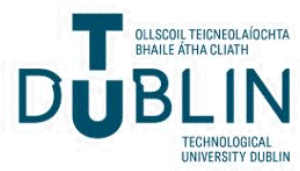




\section{Authors}

Raghavendra Jallapuram, Izabela Naydenova, Hugh Byrne, Suzanne Martin, Robert Howard, and Vincent Toal 


\title{
Raman spectroscopy for the characterization of polymerization rate in an acrylamide-based photopolymer
}

\author{
Raghavendra Jallapuram**1, Izabela Naydenova ${ }^{1}$, Hugh J. Byrne ${ }^{3}$, Suzanne Martin ${ }^{1}$, Robert Howard ${ }^{2}$ and \\ Vincent Toal ${ }^{1,2}$ \\ ${ }^{1}$ Centre for Industrial and Engineering Optics, School of Physics, \\ Dublin Institute of Technology, Dublin 8 \\ ${ }^{2}$ School of Physics, Dublin Institute of Technology, Kevin Street, Dublin 8, Ireland. \\ 3. FOCAS Institute, Dublin Institute of Technology, Camden row, Dublin 8, Ireland. \\ *corresponding author: j.raghavendra@dit.ie
}

\begin{abstract}
:
Investigations of polymerization rates in an acrylamide-based photopolymer are presented. The polymerization rate for acrylamide and methylenebisacrylamide was determined by monitoring the changes in the characteristic vibrational peaks at $1284 \mathrm{~cm}^{-1}$ and $1607 \mathrm{~cm}^{-1}$ corresponding to the bending mode of $\mathrm{CH}$ bond and $\mathrm{CC}$ double bonds of acrylamide and in the characteristic peak at $1629 \mathrm{~cm}^{-1}$ corresponding to carbon-carbon double bond of methylenebisacrylamide using Raman spectroscopy. To study the dependence of the polymerization rate on intensity and to find the dependence parameter, the polymerization rate constant was measured at different intensities.

A comparison with a commercially available photopolymer shows that the polymerization rate in this photopolymer is much faster.

Keywords: Acrylamide-based photopolymer, Raman spectroscopy, holography, polymerisation rate. OSIC codes: $090.0090,160.5335,160.5470,170.5660,260.5130$.
\end{abstract}




\section{Introduction}

Self-processing photopolymers are attractive materials for the production of easily fabricated holographic optical elements [1], for holographic data storage [2-4], the fabrication of switchable electro-optical devices [5] and the design of non-destructive optical test systems [6,7]. Besides the advantage of being self-developing, photopolymers can have high sensitivity, large dynamic range, good optical properties, low cost and are easy to prepare.

Photopolymer systems for recording holograms typically comprise one or more monomers, a photoinitiator, a binder and a sensitizing dye. Several theoretical models have been used to describe the mechanism of hologram recording in photopolymers [8-14]. Most of the models proposed are based on diffusion of monomer or mass transport when a concentration gradient of monomer is created. The basic mechanism of the hologram recording in dye sensitized photopolymers is that a dye absorbs the energy of a photon and enters to into an excited state, whereupon it reacts with an electron donor to create free radicals. These free radicals initiate the polymerization reaction. As a result when the illuminated field is spatially modulated, the conversion double to single bonds in polymerization causes a change in polarizability and hence of refractive index. In addition, a concentration gradient of the monomer is created, resulting in monomer diffusion from higher concentration regions to lower concentration regions causing a spatial modulation of the refractive index through changes in density.

Diffusion models predict that the key factor that controls the dynamics of hologram recording and the final properties of the hologram is the ratio of the diffusion and polymerization rates. The diffusion process is spatially dependent whereas the polymerization process is intensity dependent. Some of the earlier models $[9-11,14]$ assumed that the polymerization rate, which is the rate of conversion of monomer into polymer by polymerization, has a linear dependence on the intensity of light exposure. Kwon et al [12] modified this assumption and proposed a dependence of polymerization rate on the square root of the intensity. This is on the assumption that the rate of initiation is equal to the rate of termination 
and the free radical concentration is constant all through the polymerization. We believe that it is better to determine the parameter which relates the polymerization rate to the exposure intensity experimentally than to make such assumptions. To the best of our knowledge such characterization in acrylamide based photopolymer is reported in this paper for the first time.

There are some commercial photopolymer systems manufactured by companies such as Du Pont, InPhase technologies, IBM and Aprilis. In order to better understand the differences in their properties as holographic recording materials it is useful to characterize and compare their diffusion and polymerization rates. Such data is not available for all commercial photopolymers, but some of them have been characterized and reported. Moreau et al [13] characterized Du Pont's photopolymer and measured the diffusion constant at around $6.5 \times 10^{-11} \mathrm{~cm}^{2} / \mathrm{s}$. They have also characterized the polymerization constant by measuring the shrinkage during bulk polymerization, obtaining a value of $0.019 \mathrm{~s}^{-1} \mathrm{~mW}^{-0.5}$. Utilizing the methodology described for diffusion studies in [13], this acrylamide-based photopolymer was characterized in a previous publication and the monomer diffusion rate during the initial stage of grating recording was measured and has been reported [8]. As suggested above, the ratio of the diffusion rate and polymerization rate plays an important role in the dynamics of hologram recording and the final refractive index modulation, so it is necessary to also characterize the polymerization rate constant. Moreau et al characterized the polymerization in Du Pont's photopolymer on the assumption that the thickness of the photopolymer changes during polymerization and also they assume that the polymerization rate depends on the square root of exposure intensity [13].

An attempt to characterize the polymerization rate constant in a similar acrylamide-based photopolymer was made by Neipp et al. [15]. A first harmonic diffusion model proposed by Piazolla and Jenkins [16] was used. The polymerization constant was determined by fitting the temporal evolution of the transmission efficiency data during holographic recording at a spatial frequency of 1125 lines $/ \mathrm{mm}$. The polymerization rate constant for the photopolymer containing only one monomer (acrylamide) was found 
to be $0.020 \mathrm{~s}^{-1} \mathrm{~mW}^{-0.5}$. However, this was based on the assumption that the diffusion time was a constant 30 seconds during the recording and at this spatial frequency.

In the present paper, a different approach is used to measure the polymerization rate constant in an acrylamide-based photopolymer. The measurements were carried out under uniform illumination and therefore the measured polymerization rate does not depend on an assumed diffusion time.

Raman spectroscopy was used here as a direct visualisation of the photochemical process to characterize the polymerization rate. The polymerization rate was determined by studying the decrease in the intensity of two characteristic acrylamide Raman peaks during polymerization in comparison with a reference peak at $631 \mathrm{~cm}^{-1}$ which doesn't change on polymerization.

During polymerization, monomer is consumed due to polymerization where a polymer is formed. During the consumption of monomer, the $\mathrm{C}=\mathrm{C}$ double bond present in the monomer is converted into a $\mathrm{C}$ - $\mathrm{C}$ single bond. This leads to a decrease of the intensity of the associated Raman peak. The experimental setup and the results are shown in sections 3 and 4.

\section{Theory}

Raman spectroscopy has the potential to directly monitor individual constituents of a complex molecule within the sample. It has been previously utilized $[17,18]$ to characterize the consumption of acrylamide in polyacrylamide gels for radiation dosimetry. The authors observed that the consumption of monomer is monoexponentially dependent on irradiation dose.

In this study, Raman spectroscopy was used as a tool for characterizing the consumption of monomer in irradiated acrylamide-based photopolymer samples. The basic mechanism of the polymerization in this photopolymer is explained in more detail elsewhere [4]. Monomer conversion was characterized by monitoring the Raman scattering of the carbon-carbon double bond $(\mathrm{C}=\mathrm{C})$ peaks and the bending mode of the $\mathrm{C}-\mathrm{H}$ vinyl bond peak in acrylamide, as a function of illumination time. 


\section{Experimental}

The experimental set-up used in this study is shown in figure 1. A specially designed optical set-up was arranged near the Raman spectrometer to facilitate the exposure of the photopolymer layer and in-situ measurement of the polymerization rate. Photopolymer samples were prepared using gravity settling technique. The photopolymer composition consists of $8.44 \mathrm{mmol}$ of acrylamide, $1.29 \mathrm{mmol}$ of NN'methylenebisacrylamide, $0.0148 \mathrm{~mol}$ of triethanolamine and $1.25 \mu \mathrm{mol}$ of erythrosine $\mathrm{B}$ photosensitive dye. These are added to $17.5 \mathrm{ml}$ of $10 \% \mathrm{w} / \mathrm{v}$ polyvinyl alcohol stock solution prepared in distilled water. A magnetic stirrer was used to completely dissolve the monomers and to obtain a homogenous photopolymer solution. $2 \mathrm{ml}$ of the photopolymer solution was gravity settled on a 50x50 $\mathrm{cm}^{2}$ clear glass substrate. The thickness of the photopolymer layer after drying was approximately $180 \mu \mathrm{m}$.

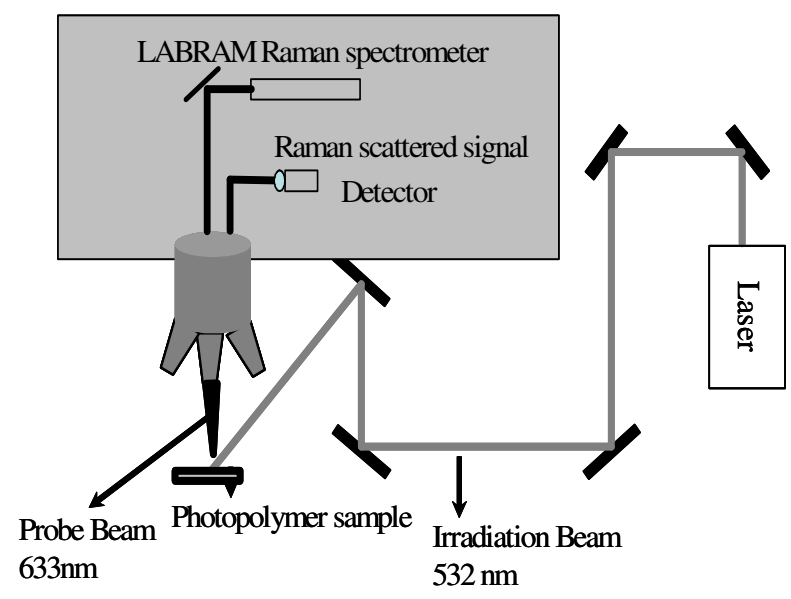

Figure 1 Experimental set-up of the Raman spectrometer and irradiation set-up.

A $532 \mathrm{~nm}$ solid state green laser was used to expose the photopolymer layer. As the system under study was insensitive to $633 \mathrm{~nm}$ and to avoid any additional changes in the sample during the measurement, a He-Ne laser $(633 \mathrm{~nm})$ with a maximum power of $20 \mathrm{~mW}$ integrated in an Instruments SA LABRAM 1B 
Raman spectrometer system was used to acquire the vibrational Raman spectrum of the photopolymer sample. The laser power of the probe beam at the sample was $\sim 7 \mathrm{~mW}$ and a $50 \mathrm{X}$ objective was employed, producing a spot size of $\sim 2 \mu \mathrm{m}$. However, the photopolymer is insensitive to the probe even for longer exposure.

\section{Results and discussion}

Vibrational Raman spectra of the individual components of the photopolymer composition, acrylamide, NN'methylenebisacrylamide, triethanolamine, erythrosine B, and polyvinyl alcohol were initially recorded and are shown in figures 2 (a) to 2 (e) respectively. The Raman spectra of the photopolymer composition containing all components except bisacrylamide and with bisacrylamide are shown in figures 3(a) and (b) respectively. From figure 3(b) it can be observed that in the spectrum of the photopolymer containing bisacrylamide an additional peak at $1629 \mathrm{~cm}^{-1}$ is present, which is not present in the spectrum of the photopolymer sample containing no bisacrylamide. This shows that the peak corresponding to 1629 $\mathrm{cm}^{-1}$ is the characteristic peak of bisacrylamide and can be assigned to the carbon-carbon double bond $(\mathrm{C}=\mathrm{C})[12]$. From the Raman spectrum of photopolymer containing no bisacrylamide (figure 3(a)) a peak at $1607 \mathrm{~cm}^{-1}$ was observed which corresponds to the acrylamide carbon-carbon double bond $(\mathrm{C}=\mathrm{C})$ [12]. From the individual Raman spectra of TEA (figure 2(c)) and PVA (figure 2(e)) it can be observed that there are no characteristic peaks above $1500 \mathrm{~cm}^{-1}$ for these components. From the Raman spectra of acrylamide monomer (figure 2(a)) and dye (figure 2(d)) it was observed that the acrylamide peak has a strong peak at $1638 \mathrm{~cm}^{-1}$ which can be ascribed to the $\mathrm{C}=\mathrm{C}$ double bond in acrylamide and from the Raman spectrum of erythrosine B dye, a very weak signal at $1606 \mathrm{~cm}^{-1}$ was observed. From figure 3(a) we assign the peak at $1607 \mathrm{~cm}^{-1}$ to acrylamide carbon-carbon double bond [12] and the peak at $1284 \mathrm{~cm}^{-1}$ was assigned to the bending mode of carbon-hydrogen $(\mathrm{CH})$ vinyl bond of the acrylamide $[11,12]$. 


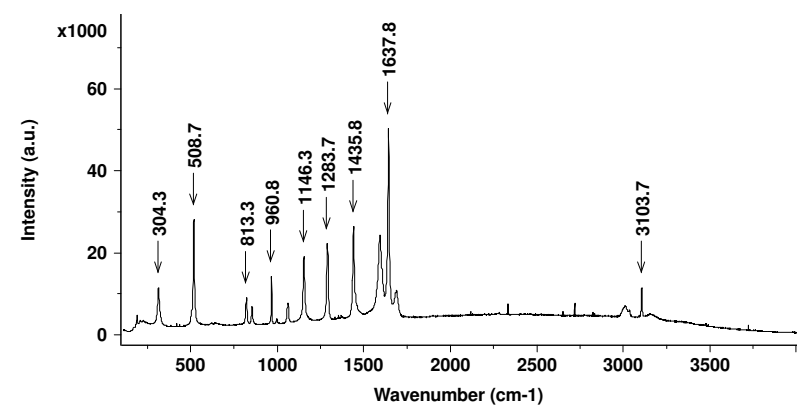

(a)

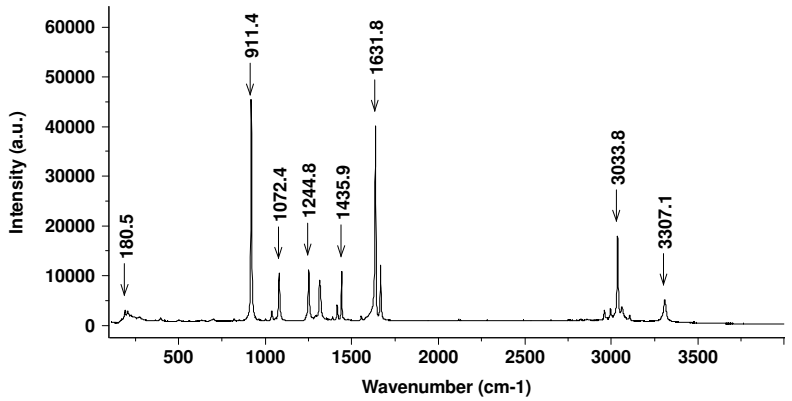

(b)

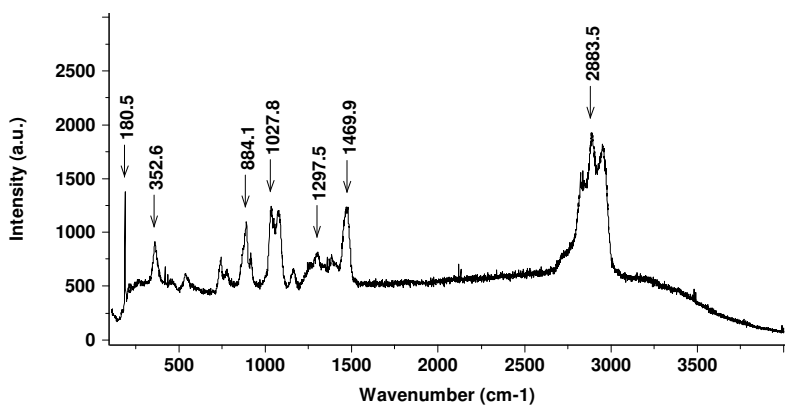

(c)

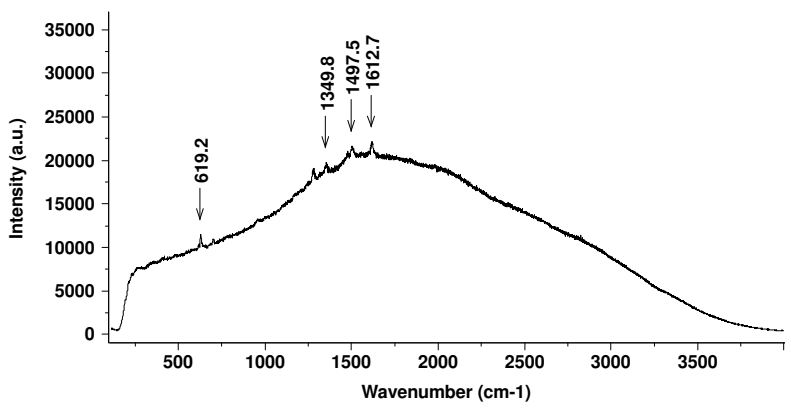

(d)

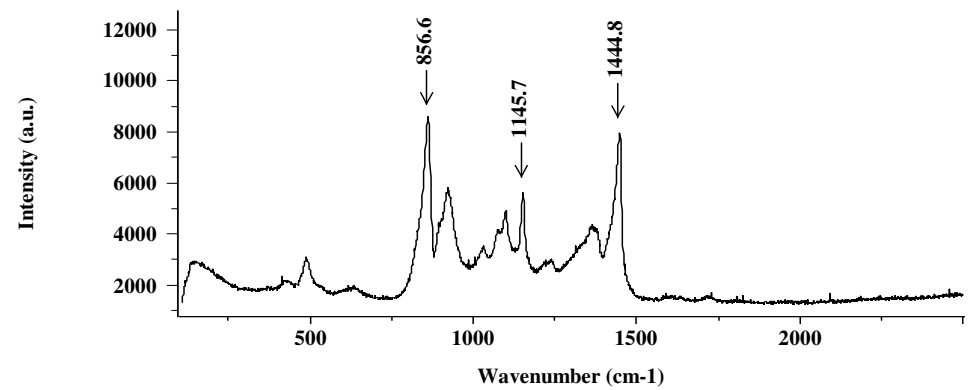

(e)

Figure 2. Raman spectrum and the characteristic peaks of (a). Acrylamide, (b). NN'methylenebisacrylamide, (c). Triethanolamine, (d). Erythrosine B, (e). Polyvinyl alcohol. 


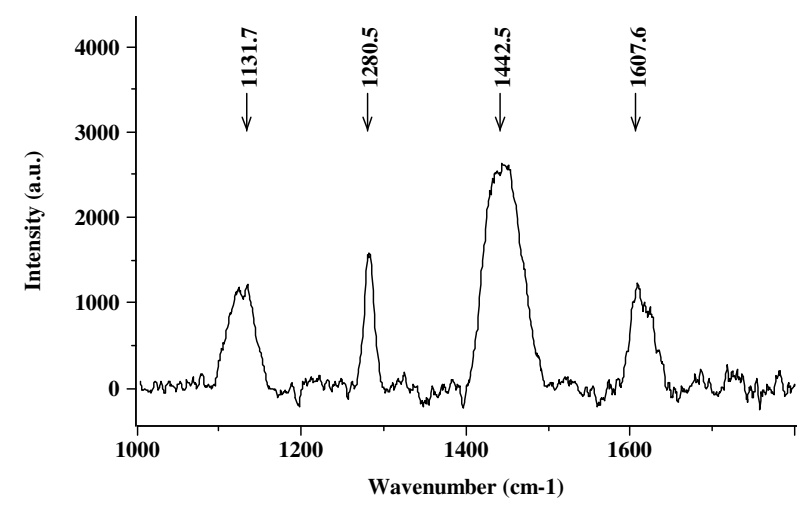

(a)

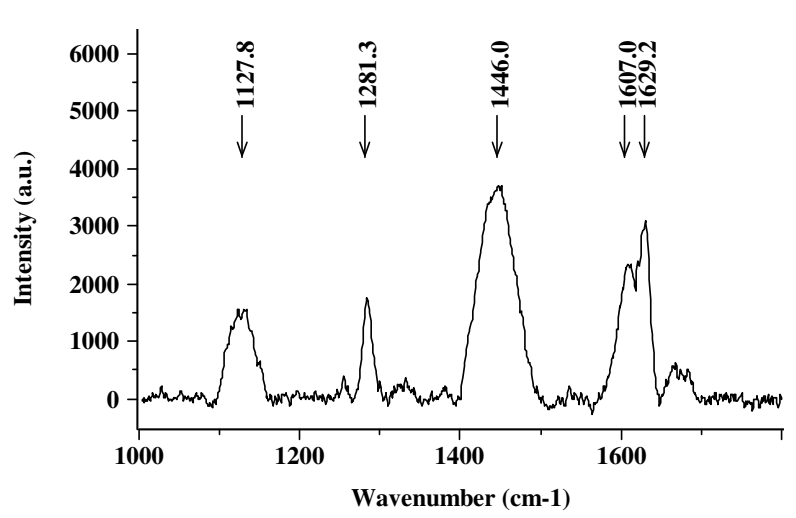

(b)

Figure 3. Raman spectrum and the characteristic peaks of photopolymer layer containing (a). Acrylamide only as a monomer and (b) both acrylamide and NN'methylene bisacrylamide as the monomers.

In order to study the dependence of the polymerization rate on intensity the photopolymer layers were exposed to uniform light intensities of $2.5,5,10,20$ and $35 \mathrm{~mW} / \mathrm{cm}^{2}$ over a $1 \mathrm{~cm}^{2}$ spot on different samples. These intensities were similar to those used during the 2-beam holographic grating recording in this photopolymer. When the photopolymer layer is exposed to the light, a polymerization reaction is initiated, consuming the monomer. In the present experimental set-up a $532 \mathrm{~nm}$ wavelength $\left(1 \mathrm{~cm}^{2}\right)$ laser spot used for exposure was overlapped with the internal $633 \mathrm{~nm}$ wavelength He-Ne laser $\sim 2 \mu \mathrm{m}$ diameter probe beam of the Raman spectrometer. During the polymerization process carbon-carbon vinyl double bonds $(\mathrm{C}=\mathrm{C})$ are converted to single bonds $(\mathrm{C}-\mathrm{C})$. This conversion of bonds on polymerization results in the decrease of the intensity peaks corresponding to the carbon-carbon double $(\mathrm{C}=\mathrm{C})$ bond at $1607 \mathrm{~cm}^{-1}$ and the bending mode of the carbon-hydrogen $(\mathrm{CH})$ vinyl bond at $1284 \mathrm{~cm}^{-1}$ for acrylamide and carboncarbon double bond at $1629 \mathrm{~cm}^{-1}$ for NN'methylenebisacrylamide when exposed with constant doses of exposure. The Raman spectra were recorded as a function of illumination time.

In the photopolymer system containing monomer and crosslinking monomer (figure 3(a) and 3(b)) the carbon-carbon double bond peaks of acrylamide and bisacrylamide were broadened considerably compared to the spectra of the individual components (figure 2(a) and (b)). Such a broadening as a result 
of environmental damping is common. The primary maximum at $1607 \mathrm{~cm}^{-1}$ corresponds to the acrylamide carbon-carbon double bond and the primary maximum at $1629 \mathrm{~cm}^{-1}$ was assigned to carbon-carbon double bond characteristic of bisacrylamide.

When the photopolymer layer was irradiated, the intensity peaks of the carbon-carbon double bond $(\mathrm{C}=\mathrm{C})$ and carbon-hydrogen vinyl bending mode $(\mathrm{CH})$ corresponding to acrylamide and the intensity peak corresponding to carbon-carbon double bond $(\mathrm{C}=\mathrm{C})$ of bisacrylamide at $1629 \mathrm{~cm}^{-1}$ decreased concurrently. An example of such a decrease in the intensity peak is shown in figures 4(a) and (b). Figure 4(a) shows the decrease in the intensity of the peaks at $1607 \mathrm{~cm}^{-1}$ and $1629 \mathrm{~cm}^{-1}$, when exposed to a constant intensity of $10 \mathrm{~mW} / \mathrm{cm}^{2}$ several times for 1 second on the same spot. A similar decrease in the intensity of the peak at $1284 \mathrm{~cm}^{-1}$ corresponding to bending mode of $\mathrm{CH}$ vinyl bond characteristic of acrylamide was observed when exposed at the same intensity of $10 \mathrm{~mW} / \mathrm{cm}^{2}$ for 1 second and is shown in figure 4(b).

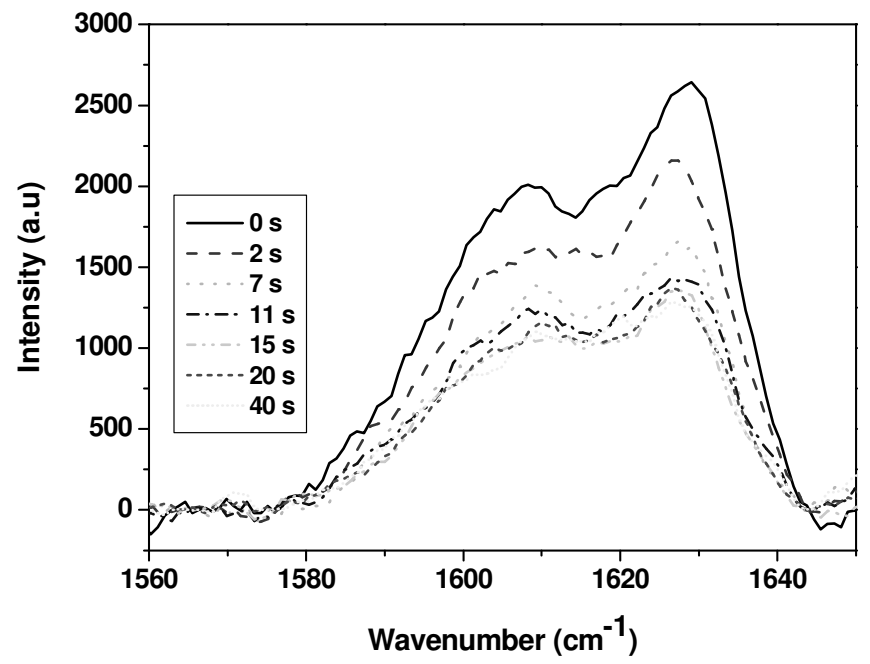

Figure 4(a). Raman spectra of photopolymer containing monomer and crosslinking monomer exposed to a constant intensity of $10 \mathrm{~mW} / \mathrm{cm}^{2}$ for 1 second each time before the spectrum is measured. The peaks correspond to $1607 \mathrm{~cm}^{-1}$ and $1629 \mathrm{~cm}^{-1}$ or acrylamide and bisacrylamide $\mathrm{C}=\mathrm{C}$ bonds respectively. 


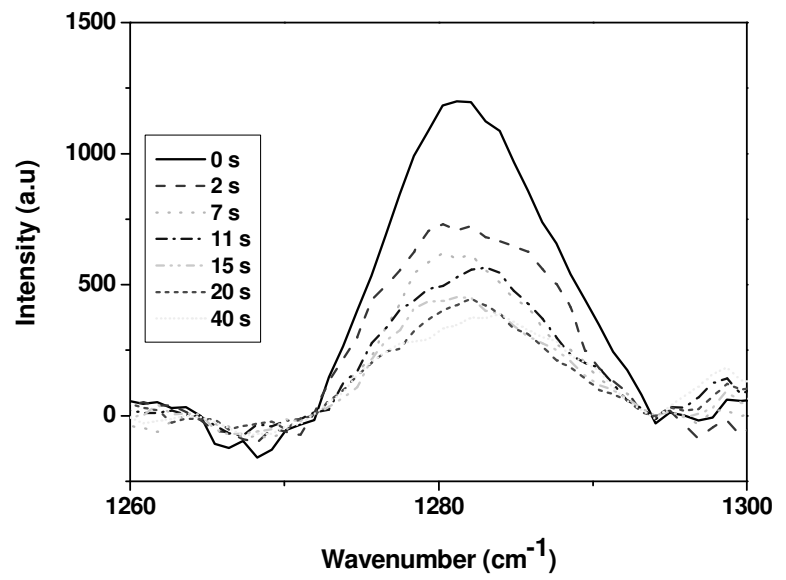

Figure 4(b). Raman spectra of photopolymer containing monomer and crosslinker exposed to a constant intensity of $10 \mathrm{~mW} / \mathrm{cm}^{2}$ for 1 second each time before the spectrum is measured. The peak corresponds to $1284 \mathrm{~cm}^{-1}$, the $\mathrm{CH}$ vinyl bond of acrylamide.

A Gaussian/Lorentzian function was used to fit the spectrum to obtain the peak height instead of taking the peak height obtained directly from the spectrum. Graphs of peak intensities versus illumination time were plotted and are shown in figures 5 (a), (b) and (c) corresponding to the characteristic peaks at 1284 $\mathrm{cm}^{-1}, 1609 \mathrm{~cm}^{-1}$ and $1629 \mathrm{~cm}^{-1}$ respectively. 


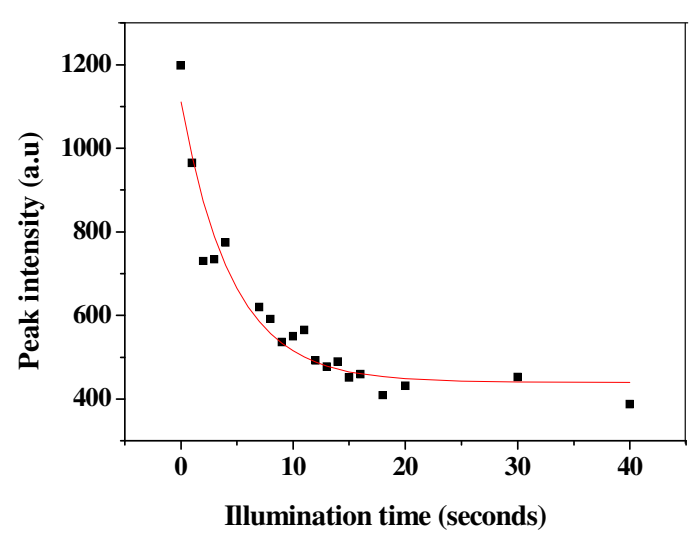

(a)

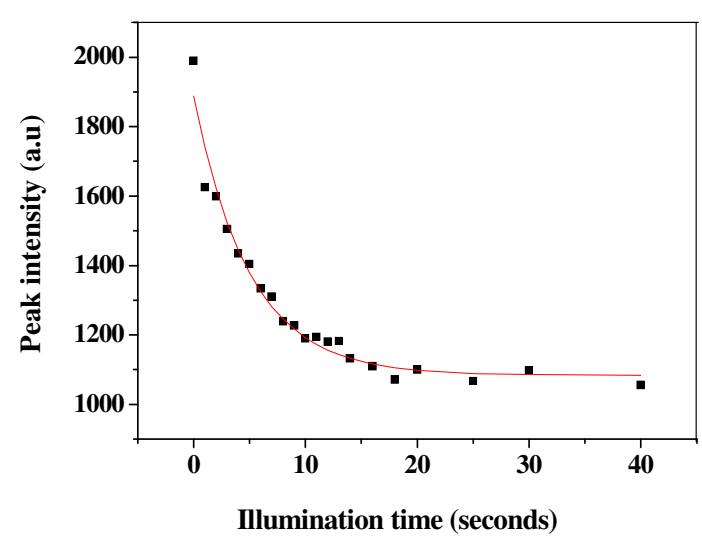

(b)

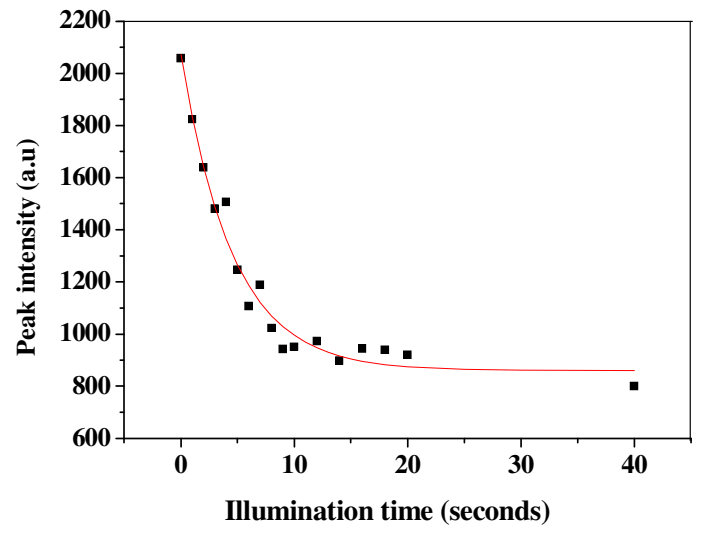

(c)

Figure 5. Graphs of peak intensity versus illumination time corresponding to (a) $\mathrm{CH}$ vinyl bond of acrylamide at $1284 \mathrm{~cm}^{-1}$, (b) carbon-carbon double bond of acrylamide at $1607 \mathrm{~cm}^{-1}$, and (c) carboncarbon double bond of NN'methylenebisacrylamide at $1629 \mathrm{~cm}^{-1}$. The solid line is a mono-exponential fitting curve and the scattered points correspond to the data points (peak intensity). The photopolymer layer was exposed to a uniform exposure intensity of $10 \mathrm{~mW} / \mathrm{cm}^{2}$. 
From the graphs it can be seen that the consumption of monomer is monoexponential. An exponential decay fit of the data gives the characteristic time constant for the decay of the scattering intensity corresponding to the acrylamide and bisacrylamide carbon-carbon double bonds $(\mathrm{C}=\mathrm{C})$ and carbonhydrogen vinyl bond $(\mathrm{CH})$.

In the early versions of the theoretical models proposed to explain the polymerization reaction kinetics for holographic recording in photopolymers [3-5], the polymerization rate was assumed to depend linearly on intensity of exposure. In the more recent studies [12] the polymerization time constant is related to the exposure intensity as shown in equation 1.

$$
\underline{1}=\mathrm{kI}^{1 / 2}
$$

$\mathrm{t}$

where $\mathrm{t}$ is polymerization time constant, $\mathrm{k}$ is polymerization rate and $\mathrm{I}$ is the intensity of illuminating light. Such assumptions are not always justifiable as the rate of polymerization also depends on the reactivity of the monomers and on their concentration. The chemical structure and functionality of monomers as well as the background polymer also could influence the polymerization rate [13]. The above equation can be written in more general way [15] as shown in equation 2.

$\frac{1}{-}=\mathrm{kI}^{\gamma}$ 2

$\mathrm{t}$

where $\gamma$ is the parameter which determines the dependence of the polymerization rate on intensity, which is of interest in this study.

The value of $\gamma$ was determined by plotting the logarithm of polymerization time constant, obtained when the photopolymer layers were exposed to different intensities, against the logarithm of the exposure intensity and the data fitted using a linear fitting function. The results are shown in figures 6 (a), (b) and (c).

In the present photopolymer composition the values of $\gamma$ obtained by fitting the data at $1284 \mathrm{~cm}^{-1}$ and $1609 \mathrm{~cm}^{-1}$ wavenumbers were found to be same, 0.27 . These peaks correspond to the carbon-hydrogen vinyl bond and carbon-carbon double bond $(\mathrm{C}=\mathrm{C})$ respectively of acrylamide. From the linear fit of the 
data points for the peak at $1629 \mathrm{~cm}^{-1}$ corresponding to carbon-carbon double bond of NN'methylenebisacrylamide, the value obtained for $\gamma$ was 0.32 . One can notice that the experimentally determined values for $\gamma$ parameter differ substantially from normally assumed value of 0.5 [ref]. It implies much weaker dependence of the polymerisation rate on the intensity of recording.

By substituting the value of polymerization time constant $t$, the polymerization rate dependence parameter $\gamma$ and exposure intensity I into equation 2, the polymerization rate of acrylamide in the photopolymer composition was calculated and the value is $0.100 \mathrm{~s}^{-1}\left(\mathrm{~mW} / \mathrm{cm}^{2}\right)^{-0.27}$. The polymerization rate constant of bisacrylamide in the photopolymer composition was also calculated and the value is $0.114 \mathrm{~s}^{-1}\left(\mathrm{~mW} / \mathrm{cm}^{2}\right)^{-0.32}$. Similar values for the polymerization rates were obtained directly from the intercept of the graph by taking the inverse logarithm of the log $\mathrm{k}$ value.

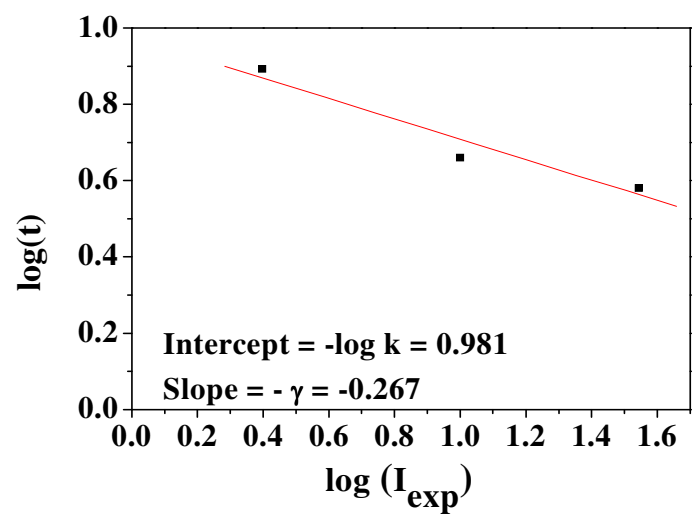

6(a)

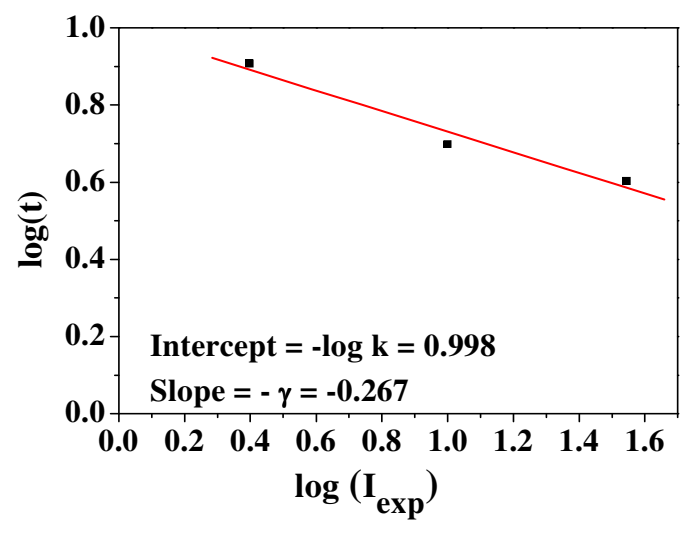

6(b) 


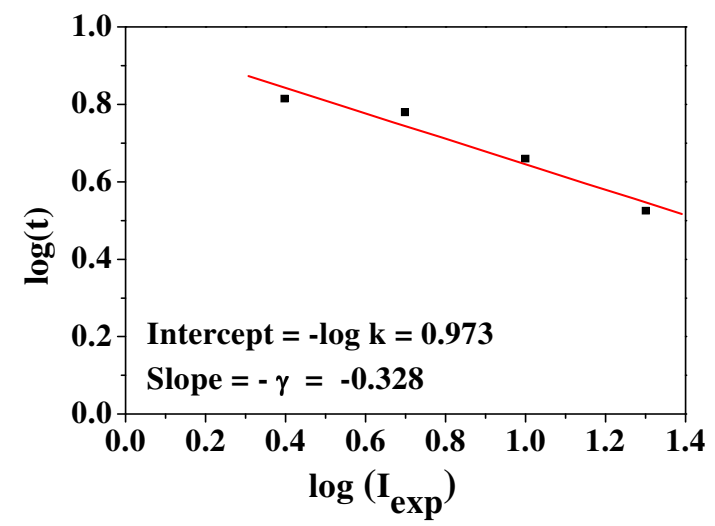

6(c)

Figure 6. A graph of $\log (\mathrm{t})$ against $\log \left(\mathrm{I}_{\mathrm{exp}}\right)$ corresponding to the (a) bending mode of $\mathrm{CH}$ vinyl bond of acrylamide at $1284 \mathrm{~cm}^{-1}$, (b) carbon-carbon double bond of acrylamide and (c) carbon-carbon double bond of NN'methylenebisacrylamide. The solid line corresponds to a linear fit of the scattered data points. $t$ is the polymerization time constant obtained at different exposure intensities.

When compared to other photopolymers such as Du Pont's whose polymerization rate was characterized as $0.019 \mathrm{~s}^{-1} \mathrm{~mW}^{-0.5}$, the photopolymer under study has almost an order of magnitude faster polymerization rate.

The measured polymerization rate is approximately five times faster than that obtained by Neipp et al [9] for a similar acrylamide-based photopolymer system. However, Neipp et al's polymerization rate depends on the assumption that the diffusion time is of the order of 30 seconds for which there is little basis given. And also the sensitizing dye used in their photopolymer composition is yellowish eosin which is different from that used in the present study. So a direct comparison may be somewhat misleading. However, in the present measurements a somewhat faster polymerization rate was obtained and the measurement does not rely on assumed diffusion rates. It should also be borne in mind that the polymerization rate in this system was estimated under spatially uniform illumination whereas, in holographic recording the actual polymerization rates are likely to be influenced by diffusion of additional monomer and a spatially varying 
supply of initiating molecules, and could be even faster. Also variations in polymerization rates would be expected due to variations in the photopolymer formulation.

\section{Conclusions}

Characterization of the polymerization rate constant in an acrylamide-based photopolymer for holographic recording using Raman spectroscopy is presented. The consumption of monomer was observed to be mono-exponential. A time constant from the exponential fit of the intensity peaks corresponding to acrylamide carbon-carbon double bond $(\mathrm{C}=\mathrm{C})$, carbon-hydrogen vinyl bond $\left(\mathrm{CH}_{2}\right)$ and carbon-carbon double bond of bisacrylamide $(\mathrm{C}=\mathrm{C})$ was obtained and the polymerization rate constant was determined. It was determined experimentally that the dependence of the polymerisation rate on the intensity is weaker than the one assumed in the commonly accepted models. The values for the $\gamma$ parameter obtained for acrylamide and NN'methylenebisacrylamide are 0.27 and 0.32 correspondingly. The polymerization constant of acrylamide in the stated photopolymer composition was found to be $0.100 \mathrm{~s}^{-1}\left(\mathrm{~mW} / \mathrm{cm}^{2}\right)^{-0.27}$ and

polymerization rate of bisacrylamide was found to be $0.114 \mathrm{~s}^{-1}\left(\mathrm{~mW} / \mathrm{cm}^{2}\right)^{-0.32}$. The polymerization rate constant in this photopolymer is faster than in other commercial photopolymers for holographic recording.

\section{Acknowledgments}

The authors would like to thank School of Physics and FOCAS for funding the project and also providing the excellent facilities to carry out the experimental work.

\section{References}

[1]. S.Guntaka, V.Toal, S.Martin, "Holographically recorded diffractive optical elements for holographic and electronic speckle pattern interferometry", Appl.Opt., 41, 7475-7479 (2002).

[2]. R.T.Ingwall, D.A.Waldman, H.J.Caufal, D.Psaltis, G.T.Sincerbox, "Holographic data storage", Springer Series in Optical Sciences, New York, 76, CH. Photopolymer systems, 171-197 (2000). 
[3]. H. Sherif, I. Naydenova, S. Martin, C. McGinn, and V. Toal, Characterisation of an acrylamide-based photopolymer for data storage utilizing holographic angular multiplexing, J. Opt. A: Pure Appl. Opt, 7, 255-260 (2005).

[4]. R. Jallapuram, I. Naydenova, S. Martin, R. Howard, V. Toal, Sven Frohmann, Susanna Orlic, Hans J Eichler, "Acrylamide based photopolymer for micro-holographic data storage", Opt. Mat., 28, 329333 (2006).

[5]. K. Pavani, I. Naydenova, S. Martin, R. Jallapuram, R. G. Howard, V. Toal, “Electro-optical switching of liquid crystal diffraction gratings by using surface relief effect in the photopolymer." Opt. Comm., 273, 367-369 (2007).

[6]. E. Mihaylova, I. Naydenova, S. Martin, V. Toal, "Electronic spackle pattern shearing interferometer with a photopolymer holographic grating", Appl. Opt., 43, 2439 (2004).

[7]. S.R.Guntaka, V. Toal, S. Martin, "Holographic and Electronic Speckle-Pattern Interferometry using a Photopolymer Recording Material”, Strain, 40, 79-82 (2004).

[8]. I.Naydenova, R.Jallapuram, R.Howard, S.Martin, V.Toal, "Investigation of the diffusion processes in a self-processing acrylamide-based photopolymer system”, Appl. Opt., 43, 2900-2905 (2004).

[9]. I.Aubrecht, M.Miler, I.Koudela, "Recording of holographic diffraction gratins in photopolymers: theoretical modeling and real-time monitoring of grating growth”, J. Mod. Opt., 45, 1465-1477 (1998)

[10]. W.S.Colburn, K.A.Haines, "Volume hologram formation in photopolymer materials", Appl. Opt., 10, 1636-1641 (1971).

[11]. V.L.Colvin, R.G.Larson, A.L.Harris, M.L.Shilling, "Quantitative model of volume hologram formation in photopolymers", J. App. Phys., 81, 5913-5923 (1997).

[12]. J.H.Kwon, H.C.Hwang, K.C.Woo, "Analysis of temporal behavior of beams diffracted by volume gratings formed in photopolymers", J. Opt. Soc. Am. B, 16, 1651-1657 (1999).

[13]. V. Moreau, Y. Renotte, Y. Lion, "Characterization of Du-Pont photopolymer: determination of kinetic parameters in a diffusion model”, Appl.Opt. 41, 3427-3435 (2002). 
[14]. G. Zhao, P. Mouroulis, "Diffusion model of hologram formation in dry photopolymer materials," J. Mod. Opt. 41, 1929-1939 (1994).

[15]. C.Neipp, S.Gallego, M.Ortuno, A.Marquez, A.Belendez, I.Pascual, "Characterization of a PVA/acrylamide photopolymer: Influence of a cross-linking monomer in the final characteristics of the hologram", Opt. Comm., 224, 27-34 (2003).

[16]. S.Piazzolla, B.K.Jenkins, "First-harmonic diffusion model for holographic grating formation in photopolymers", J.Opt. Soc. Am. B, 17, 1147-1157 (2000).

[17]. A.I.Jirasek, C.Duzenli, C.Audet, J.Eldridge, "Characterization of monomer/crosslinker consumption and polymer formation observed in FT-Raman spectra of irradiated polyacrylamide gels", Phys.Med. Biol. 46, 151-165 (2001).

[18]. C.Baldock, L.Rintoul, S.F.Keevil, J.M.Pope, G.A.George, "Fourier transform Raman spectroscopy of acrylamide gels (PAGs) for radiation dosimetry” Phys. Med. Biol. 43, 36173627 (1998). 